\title{
Regulation of oxidative stress and inflammation by glycaemic control: evidence for reversible activation of the 5-lipoxygenase pathway in type 1 diabetes, but not in type 2 diabetes
}

\author{
R. Boizel • G. Bruttmann • P. Y. Benhamou • S. Halimi • \\ F. Stanke-Labesque
}

Received: 4 March 2010 /Accepted: 20 May 2010 / Published online: 10 June 2010

(C) Springer-Verlag 2010

Keywords 11-Dehydro-thromboxane $\mathrm{B}_{2} \cdot$ Diabetes .

Glycaemic control $\cdot$ Leukotriene $\mathrm{E}_{4} \cdot 5$-Lipoxygenase

$\begin{array}{ll}\text { Abbreviations } \\ \text { CRP } & \text { C-reactive protein } \\ \text { CysLT } & \text { Cysteinyl leukotriene } \\ \text { ICAM-1 } & \text { Intercellular adhesion molecule 1 } \\ \text { PGF }_{2} & \text { Prostaglandin } F_{2} \\ \mathrm{TXB}_{2} & \text { Thromboxane } \mathrm{B}_{2}\end{array}$

To the Editor: Additional studies are needed to clarify the impact of improved glycaemic control on cardiovascular diseases in both types of diabetes. Monnier et al. recently investigated the excretion rate of 8-iso-prostaglandin $\mathrm{F}_{2}$ $\left(\mathrm{PGF}_{2}\right)_{\alpha}$ in patients with type 2 diabetes. They concluded that this biomarker of oxidative stress is increased in patients with type 2 diabetes treated with oral hypoglycaemic agents

\footnotetext{
R. Boizel · G. Bruttmann · P. Y. Benhamou • S. Halimi Department of Endocrinology-Diabetology-Nutrition, Grenoble University Hospital,

Grenoble, France

F. Stanke-Labesque $(\bowtie)$

Laboratory of Pharmacology, Grenoble University Hospital, BP217, 38043 Grenoble Cedex 09, France

e-mail: FStanke@chu-grenoble.fr

F. Stanke-Labesque

Research Laboratory HP2 INSERM ERI17,

University of Medicine,

La Tronche, France

vs patients with type 1 diabetes and that add-on insulin resulted in a decrease of 8 -iso- $\mathrm{PGF}_{2 \alpha}$ excretion [1]. To address the impact of intensive therapy on the excretion of other arachidonic acid derivatives, we investigated the effect of a 3-month improvement of glycaemic control by intensive insulin treatment on the urinary excretion of leukotriene $E_{4}$ and 11-dehydro-thromboxane $\mathrm{B}_{2}$ (11-dehydro-TXB $\mathrm{B}_{2}$ ) in consecutive patients with baseline $\mathrm{HbA}_{1 \mathrm{c}}>8.5 \%, 20$ of whom had type 1 diabetes and 19 type 2 diabetes. Leukotrienes are arachidonic acid metabolites that are derived from the 5-lipoxygenase pathway and possess vasoactive, chemotactic and pro-inflammatory properties. Sufficient evidence suggests that 5-lipoxygenase pathway activation plays a role in the pathogenesis of cardiovascular diseases [2] and that leukotriene $\mathrm{E}_{4}$ urinary excretion is a validated marker of in vivo cysteinyl leukotrienes (CysLTs) activation [3, 4]. Leukotriene $\mathrm{E}_{4}$ urinary excretion is increased in poorly controlled patients with type 1 diabetes as compared with age-matched controls [4].

The study protocol was approved by the local Ethical Committee and all participants provided informed written consent. Patients with asthma or any pulmonary disease known to enhance leukotriene $\mathrm{E}_{4}$ urinary excretion, heart failure, history of malignancy, recent infectious disease or plasma creatinine $>180 \mu \mathrm{mol} / 1$ were excluded, as were patients treated with corticosteroids, pregnant women and smokers. Patient characteristics are detailed in Table 1; a more intensive treatment (participation in a structured education programme, insulin initiation or dosage revision) was justified in all patients. Interestingly, insulin therapy had been previously initiated in $47 \%$ of patients with type 2 diabetes, with duration of insulin treatment longer than 2 years in three of nine patients; it was applied to all 
Table 1 Baseline characteristics of the study population

\begin{tabular}{lll}
\hline Characteristic & Type 1 diabetes & Type 2 diabetes \\
\hline$n$ & 20 & 19 \\
Age (years) & $37 \pm 12$ & $58 \pm 12$ \\
Men (\%) & 45.0 & 68.4 \\
Waist (cm) & $82 \pm 11$ & $109 \pm 14$ \\
Diabetes duration (years) & $14.5(5-22)$ & $11(10-15.5)$ \\
Retinopathy (\%) & 40 & 26.3 \\
UAE >2.5 mg/mmol & 10 & 26.3 \\
$\quad$ creatinine (\%) & 20 & 73.7 \\
Hypertension (\%) & 5 & 23.5 \\
Cardiovascular disease (\%) & 5 & \\
\hline
\end{tabular}

Unless otherwise indicated, data are presented as means $\pm \mathrm{SD}$ or medians (interquartile ranges) according to the distribution of respective values, or percentages

UAE, urinary albumin excretion

patients entering this trial. Estimated glomerular filtration rate was $>80 \mathrm{ml} / \mathrm{min}$ in all patients with type 1 (mean $\pm \mathrm{SD}$ : $108 \pm 20$ ) and $>70 \mathrm{ml} / \mathrm{min}$ in all patients with type 2 diabetes (mean \pm SD: $119 \pm 44$ ). Patient follow-up included an early visit to check the efficacy and safety of the revised treatment and the end-of-study visit ( 25 to 35 and 80 to 100 days after inclusion, respectively). At baseline and end of study, each patient performed an overnight urine collection and blood was drawn after a $12 \mathrm{~h}$ overnight fast.
Quantification of leukotriene $\mathrm{E}_{4}$ and 11-dehydro- $\mathrm{TXB}_{2}$ was performed by liquid chromatography tandem mass spectrometry in urine samples stored at $-80^{\circ} \mathrm{C}$ until analysis using methods previously described [4]. The limits of detection were 10 and $100 \mathrm{pg} / \mathrm{ml}$ of urine for leukotriene $\mathrm{E}_{4}$ and 11-dehydro- $\mathrm{TXB}_{2}$ respectively; inter-and intra-assay variation were $<6 \%$.

Baseline urinary leukotriene $\mathrm{E}_{4}$ and 11-dehydro- $\mathrm{TXB}_{2}$ ( $\mathrm{pg} / \mathrm{mg}$ of creatinine), and high-sensitivity C-reactive protein (CRP) concentrations were not significantly different in type 1 and type 2 diabetes groups (Table 2). Baseline serum soluble intercellular adhesion molecule-1 (ICAM-1) was higher in patients with type 2 than in those with type 1 diabetes $(p=0.017)$. Our data confirmed high leukotriene $\mathrm{E}_{4}$ urinary excretion in patients with type 1 diabetes and showed similar values in poorly controlled patients with type 2 diabetes. Baseline urinary leukotriene $\mathrm{E}_{4}$ and 11-dehydro$\mathrm{TXB}_{2}$ were similar in the type 2 diabetes subgroups receiving and not receiving insulin before the intensive treatment period $(p=0.5)$. In a subset of 11 patients with type 1 diabetes, an additional sampling was possible 5 days after baseline in those in an ongoing education programme; leukotriene $\mathrm{E}_{4}$ urinary excretion was not different at this stage vs baseline (data not shown).

After a 3 month period of intensive glycaemic control (details on insulin therapy, see Table 2), $\mathrm{HbA}_{1 \mathrm{c}}$ and 11dehydro- $\mathrm{TXB}_{2}$ urinary excretion significantly decreased in

Table 2 Effect of intensive glycaemic control on BMI, and inflammatory and metabolic variables according to diabetes type

\begin{tabular}{|c|c|c|c|c|}
\hline \multirow[t]{2}{*}{ Variable } & \multicolumn{2}{|c|}{ Type 1 diabetes } & \multicolumn{2}{|c|}{ Type 2 diabetes } \\
\hline & Baseline & After intensive treatment 1 & Baseline & After intensive treatment 2 \\
\hline $\mathrm{HbA}_{1 \mathrm{c}}(\%)$ & $9.7 \pm 1.4$ & $7.8 \pm 1.1^{\mathrm{a}}$ & $10.1 \pm 1.3$ & $7.3 \pm 1.4^{\mathrm{a}}$ \\
\hline BMI $\left(\mathrm{kg} / \mathrm{m}^{2}\right)$ & $23.9 \pm 2.9$ & $23.7 \pm 2.5$ & $32.3 \pm 5.0$ & $31.3 \pm 4.3$ \\
\hline $\mathrm{LTE}_{4}(\mathrm{pg} / \mathrm{mg} \text { creatinine })^{\mathrm{c}}$ & $72 \pm 48$ & $49 \pm 31^{\mathrm{a}}$ & $86 \pm 57$ & $81 \pm 58$ \\
\hline 11-dehydro- $\mathrm{TXB}_{2}(\mathrm{pg} / \mathrm{mg} \text { creatinine })^{\mathrm{c}}$ & $898 \pm 495$ & $596 \pm 279^{b}$ & $1,037 \pm 820$ & $564 \pm 531^{\mathrm{a}}$ \\
\hline High sensitivity CRP (mg/l) & $1.1(0.7-2.0)$ & $1.5(0.5-2.2)$ & $3.1(2.5-4.8)$ & $2.8(1.2-5.4)$ \\
\hline Fibrinogen (g/l) & $2.9 \pm 0.4$ & $3.1 \pm 0.6$ & $3.5 \pm 0.9$ & $3.6 \pm 0.8$ \\
\hline Soluble ICAM-1 ( $\mu \mathrm{g} / \mathrm{l})$ & $220 \pm 38$ & $214 \pm 79$ & $298 \pm 131$ & $295 \pm 121$ \\
\hline Total cholesterol (mmol/l) & $4.5 \pm 1.0$ & $5.0 \pm 0.8$ & $5.0 \pm 1.0$ & $4.4 \pm 1.1$ \\
\hline HDL-cholesterol (mmol/1) & $1.8 \pm 0.4$ & $2.0 \pm 0.4$ & $1.2 \pm 0.3$ & $1.2 \pm 0.4$ \\
\hline Triacylglycerol (mmol/l) & $0.9(0.7-1.1)$ & $0.7(0.6-1.0)$ & $2.2(1.5-3.5)$ & $1.7(1.1-2.7)^{\mathrm{a}}$ \\
\hline
\end{tabular}

Unless otherwise indicated, data are presented as means \pm SD or medians (interquartile ranges) according to the distribution of respective values Intensive treatment 1: implementation of flexible insulin therapy: $0.67 \pm 0.29 \mathrm{IU} \mathrm{kg}^{-1} \mathrm{day}^{-1}, 53 \pm 8 \%$ of the dose as bolus insulin (assumption: $210 \mathrm{~g}$ carbohydrate per day, normal pre-meal blood glucose and no extra bolus)

Intensive treatment 2: for patients not previously treated with insulin: $0.19 \pm 0.08 \mathrm{IU} \mathrm{kg}^{-1}$ day $^{-1}$ as basal $(n=10)$ and one multiple daily injection (MDI) regimen (0.78 IU kg-1 day ${ }^{-1}$ ); for patients previously treated with insulin: $0.88 \pm 0.43 \mathrm{IU} \mathrm{kg}^{-1} \mathrm{day}^{-1}$ (MDI, corrective pre-meal dose not included, $n=9)$ vs $0.66 \pm 0.24 \mathrm{IU} \mathrm{kg}^{-1} \mathrm{day}^{-1}$ at baseline

${ }^{\mathrm{a}} p<0.001$ vs baseline; ${ }^{\mathrm{b}} p<0.05$ vs baseline

${ }^{\mathrm{c}}$ To convert $\mathrm{pg} / \mathrm{mg}$ creatinine to $\mathrm{pg} / \mathrm{mmol}$ creatinine, multiply values by 113.12

$\mathrm{LTE}_{4}$, leukotriene $\mathrm{E}_{4}$ 
both groups, whereas body weight did not change. Leukotriene $\mathrm{E}_{4}$ urinary excretion decreased by $32 \%$ in type 1 diabetes patients ( $p=0.008$ vs baseline), but did not decrease in patients with type 2 diabetes (Table 2). In the type 1 diabetes group, baseline leukotriene $\mathrm{E}_{4}$ and the change in $\mathrm{HbA}_{1 \mathrm{c}}$ were correlated to baseline $\mathrm{HbA}_{1 \mathrm{c}}(r=0.55$, $p=0.015$ and $r=0.77, p<0.001$ respectively). The change in leukotriene $\mathrm{E}_{4}$ urinary excretion was correlated to baseline leukotriene $\mathrm{E}_{4}$ urinary excretion, baseline $\mathrm{HbA}_{1 \mathrm{c}}$ and to the change in $\mathrm{HbA}_{1 \mathrm{c}}(r=0.78, p<0.001, r=0.62, p=0.006$ and $r=0.46, p=0.050$ respectively).

We had provided preliminary evidence of the link between hyperglycaemia and the CysLT pathway activation in an animal model of type 1 diabetes (insulin treatment in streptozotocin rats significantly reduced leukotriene $\mathrm{E}_{4}$ urinary excretion) and also reported that leukotriene $\mathrm{E}_{4}$ urinary excretion was significantly enhanced in patients with poorly controlled type 1 diabetes [3, 4]. The present investigation suggests that hyperglycaemia induces a reversible activation of the 5-lipoxygenase and thromboxane pathways in type 1 diabetes. Intensive diabetes management had no effect on other inflammatory biomarkers (soluble ICAM-1, high-sensitivity CRP) in this study population and did not reduce leukotriene $\mathrm{E}_{4}$ urinary excretion in the type 2 diabetes group. Nevertheless, the decrease urinary excretion of 11-dehydro- $\mathrm{TXB}_{2}$ in the type 2 diabetes group confirms the change previously reported after 4 weeks of intensive insulin therapy in patients with poorly controlled type 2 diabetes [5]. The reversible activation of the 5-lipoxygenase pathway related to chronic hyperglycaemia in type 1 is consistent with cardiovascular diseases appearing to be strongly glucose-mediated in this type of diabetes. Indeed, interventions targeting blood glucose could prevent cardiovascular diseases to a greater extent in type 1 than in type 2 diabetes; moreover, cardiovascular diseases might be more strongly glucose-mediated in type 1 diabetes $[6,7]$.

A similar 3 month improvement of hyperglycaemia did not change leukotriene $\mathrm{E}_{4}$ urinary excretion in type 2 diabetes, which suggests that activation of the CysLT pathway was unchanged in this type of diabetes, a finding associated with multifactorial underlying inflammation (i.e. related to adipokines). Overall, the pathophysiology of oxidative stress and inflammation is complex and does not follow the same patterns according to the type of diabetes [8]. Multifactorial proinflammatory cell activation cannot be markedly modified by improved glycaemic control in type
2 diabetes. In contrast, in type 1 diabetes, hyperglycaemiadependent reactive oxygen species (ROS) generation might be a crucial determinant of inflammation; moreover, flexible insulin therapy might reduce glucose variability.

We conclude that hyperglycaemia induced activation of the 5-lipoxygenase pathway in both types of diabetes, with a partial correction being achieved by intensive insulin therapy in patients with type 1 , but not in those with type 2 diabetes.

Trial registration ClinicalTrials.gov NCT00324792

Funding This work was supported by a grant from the University Hospital of Grenoble, France (Direction Régionale de la Recherche Clinique).

Acknowledgements The authors are grateful to C. Nahum and K. Scalabrino for expert technical assistance.

Duality of interest The authors declare that there is no duality of interest associated with this manuscript.

\section{References}

1. Monnier L, Colette C, Mas E et al (2010) Regulation of oxidative stress by glycaemic control: evidence for an independent inhibitory effect of insulin therapy. Diabetologia 53:562-571

2. Peters-Golden M, Henderson WR Jr (2007) Leukotrienes. N Engl J Med 357:1841-1854

3. Hardy G, Stanke-Labesque F, Peoc'h M et al (2001) Cysteinyl leukotrienes modulate angiotensin II constrictor effects on aortas from streptozotocin-induced diabetic rats. Arterioscler Thromb Vasc Biol 21:1751-1758

4. Hardy G, Boizel R, Bessard J et al (2005) Urinary leukotriene E4 excretion is increased in type 1 diabetic patients: a quantification by liquid chromatography-tandem mass spectrometry. Prostaglandins Other Lipid Mediat 78:291-299

5. Santilli F, Davi G, Consoli A et al (2006) Thromboxane-dependent CD40 ligand release in type 2 diabetes mellitus. J Am Coll Cardiol 47:391-397

6. The Diabetes Control and Complications Trial/Epidemiology of Diabetes Interventions and Complications (DCCT/EDIC) Study Research Group (2005) Intensive diabetes treatment and cardiovascular disease in patients with type 1 diabetes. N Engl J Med 353:2643-2653

7. Holman RR, Paul SK, Bethel MA, Matthews DR, Neil HA (2008) 10 -year follow-up of intensive glucose control in type 2 diabetes. N Engl J Med 359:1577-1589

8. Humpert PM (2010) Oxidative stress and glucose metabolism: is there a need to revisit effects of insulin treatment? Diabetologia 53:403-405 